\title{
Decadal variability of heat content in the South China Sea inferred from observation data and an ocean data assimilation product
}

\author{
Wei Song ${ }^{1,2}$, Jian Lan ${ }^{1}$, Qinyan Liu' ${ }^{2}$, Dandan Sui ${ }^{2}$, Lili Zeng ${ }^{2}$, and Dongxiao Wang ${ }^{2}$ \\ ${ }^{1}$ Physical Oceanography Laboratory, Ocean University of China, Qingdao, China \\ ${ }^{2}$ State Key Laboratory of Tropical Oceanography, South China Sea Institute of Oceanology, Chinese Academy of Sciences, \\ Guangzhou, China
}

Correspondence to: Dongxiao Wang (dxwang@scsio.ac.cn)

Received: 2 May 2013 - Published in Ocean Sci. Discuss.: 8 August 2013

Revised: 2 January 2014 - Accepted: 16 January 2014 - Published: 24 February 2014

\begin{abstract}
Using an observation data set of temperature and the Simple Ocean Data Assimilation (SODA), the decadal variability of upper ocean heat content (0-400 m; hereafter, $\mathrm{OHC}$ ) in the South China Sea (SCS) was investigated for the period from 1958 to 2007. Decadal variability was identified as the dominant mode of upper OHC besides the seasonal cycle. According to decreasing or increasing $\mathrm{OHC}$, four periods were chosen to discuss detailed processes behind OHC variability in the SCS; the four periods are 19581968, 1969-1981, 1982-1992, and 1993-2003. Results show that advection was the major factor for decreasing (increasing) OHC during 1958-1968 (1968-1981). During 19821992 and 1993-2003, the net surface heat flux was the main contributor to the variability of $\mathrm{OHC}$ besides the advection. The OHC, advection and net surface heat flux had significant positive trends during 1992-2003. The spatial characteristics of OHC variability and heat budget in the Luzon Strait, west of Luzon Island, and in the Xisha warm eddy region are also discussed.
\end{abstract}

\section{Introduction}

The ocean has the greatest heat capacity in the climate system. Significant changes in the global ocean heat content were revealed for the past $50 \mathrm{yr}$ (Levitus et al., 2000). To understand the ocean's roles in the climate system, the global ocean's ability to store and transport heat has been extensively studied by a number of researchers. Most of the recent studies focused on upper ocean warming (Levitus et al., 2000, 2005, 2009; Gouretski and Koltermann, 2007;
Domingues et al., 2008) in association with the ocean's significant contribution to global warming and climate change.

The South China Sea (SCS) is the largest marginal sea in Southeast Asian waters (Fig. 1). It is connected to the East China Sea through the Taiwan Strait, to the Pacific Ocean through the Luzon Strait, and to the Sulu Sea via the Mindoro Strait. There are also channels connecting the SCS and the Indian Ocean: the Karimata Strait and the Malacca Strait. In this paper, we choose a cross section covering the two straits and call it the Sunda shelf (the location is given in Sect. 3). The interannual variability of latent and sensible heat fluxes in the SCS has been studied (Zong et al., 2010). $\mathrm{He}$ and Guan (1997) discussed the interannual and interdecadal variations in the upper ocean heat content $(\mathrm{OHC})$ of the SCS, and pointed out that the vertically averaged temperature trend changed from negative to positive in the recent decades. OHC contributes interdecadal variability to ENSO events, the Asian winter monsoon and the tropical atmospheric circulation anomalies (He and Guan, 1997). The OHC in the northern SCS shows propagation, but that in the southern SCS is stationary (Yan et al., 2010). Studying interdecadal variability of the $\mathrm{OHC}$ itself is not enough, because ocean circulations play an important role as well. A few studies (Fang et al., 2003; Qu et al., 2004; Willis et al., 2004; Wang et al., 2006a, b; Liu et al., 2012) pointed out that the Luzon Strait allows the ENSO signal into the SCS, and therefore the role of advection should not be neglected. Horizontal advection is especially important to the OHC during the mature phase of ENSO events (Liu et al., 2012). 


\section{Data and methods}

The data used in the present study include the expendable bathythermograph (XBT) data from the World Ocean Database 09 (WOD09) and the Simple Ocean Data Assimilation (SODA, Carton et al., 2000a, b; Carton and Giese, 2008), covering the period from 1958 to 2007. The ocean model used in making the SODA is based on Parallel Ocean Program (POP; Smith et al., 1992) physics with an average resolution of $0.25^{\circ} \times 0.4^{\circ}$ and 40 levels. The observations include virtually all available hydrographic profile data, ocean station data, moored temperature and salinity time series, surface temperature and salinity observations of various types, and night-time infrared satellite sea-surface temperature (SST) data. The SODA output is in monthly-averaged form, mapped onto uniform $0.5^{\circ} \times 0.5^{\circ}$ grids. Before the analysis, the XBT data had already been processed under quality control. We first selected the data by removing those profiles that were flagged as "bad" or as not passing the monthly, seasonal, and annual standard deviation checks. Detailed procedures are as follows. The data is flagged if it is more than $n$ standard deviation (STD) from the climatological monthly mean at any one depth. For depths deeper than $50 \mathrm{~m}, n=3$ is assigned, while for depths shallower than $50 \mathrm{~m}, n=4$ is assigned to accommodate greater variability of upper ocean states (Locarnini et al., 2006). We then removed those profiles that did not extend to $50 \mathrm{~m}$, thus eliminating profiles over the shallow continental shelf, and those profiles with obviously erroneous records (e.g., temperature $<10^{\circ} \mathrm{C}$ ) or exceptionally large vertical increment $(>20 \mathrm{~m})$ between two samples in the top $100 \mathrm{~m}$. The final data set contains a total of 23356 temperature profiles in the SCS (Fig. 1), with irregular spatial and temporal distributions.

A heat budget calculation was carried out: the heat content change is equal to the summation of surface heat fluxes, advection flux, and diffusion as in $\mathrm{Na}$ et al. (2012). The equation is:

$\mathrm{HCC}=\mathrm{QNET}+\mathrm{ADV}+R$.

In Eq. (1), HCC denotes heat-content change in the upper $400 \mathrm{~m}$. QNET (positive into the SCS) denotes the net surface heat flux. ADV (positive into the SCS) is the lateral ocean heat advection, and $\mathrm{R}$ is the residual heat flux (vertical advection, diffusion, etc.) The heat content used in the calculation is the integration of the top $400 \mathrm{~m}$, which contain the thermocline process (Qu et al., 2004). The surface heat fluxes are from the NCEP/NCAR Reanalysis 1 data set, which provides four kinds of air-sea fluxes from the study period. To discuss the monthly anomaly, the climatological seasonal cycle is removed: every month in the time series minus the mean of corresponding month. For example, the anomaly in January 1958 is the $\mathrm{HC}$ minus the average for all Januaries from 1958 to 2007.

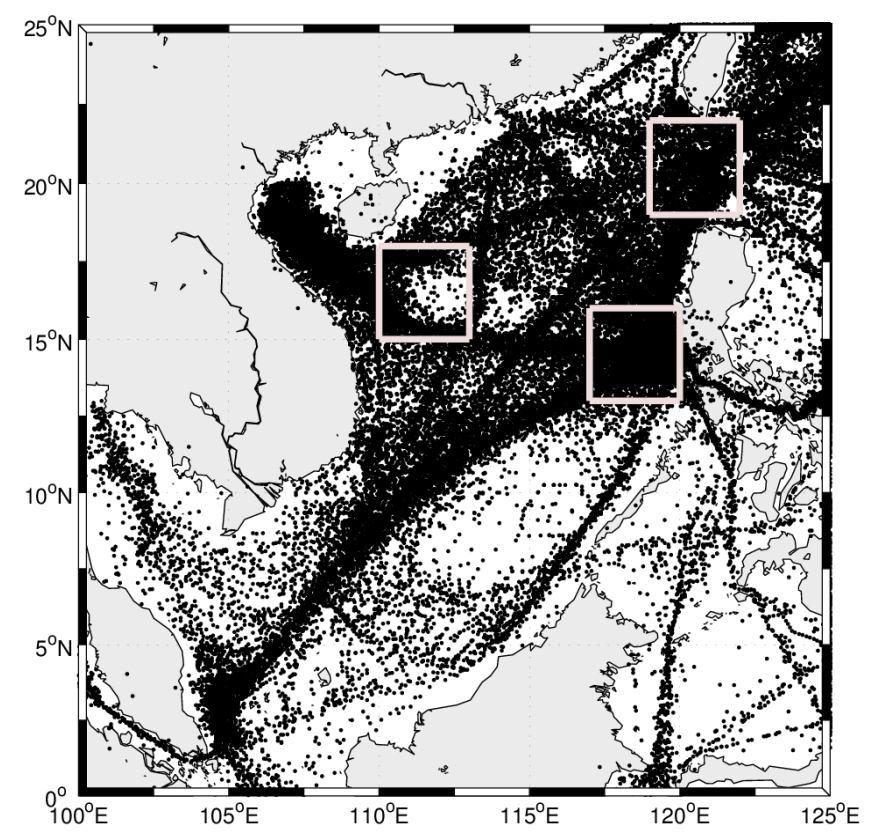

Fig. 1. Geographical distribution (asterisks) of the XBT data used in this study, which consist of more than 23000 profiles. The three boxes are used for illustrating spatial differences: Box 1 for the Luzon Strait, Box 2 for west of Luzon Island, and Box 3 for the Xisha warm eddy.

\section{Results}

\subsection{Decadal variability}

Figure 2 shows the decadal variability of vertical temperature profiles and $\mathrm{OHC}$ in the SCS $\left(90-121^{\circ} \mathrm{E}, 0-25^{\circ} \mathrm{N}\right)$. The results show that there are two dominant peaks and troughs from 1958 to 2007. The vertical temperature evolution averaged in the SCS inferred from the SODA data set shows obvious decadal variability (Fig. 2, middle), which is more evident than that inferred from the XBT data set. The strongest temperature anomalies in 100-200 $\mathrm{m}$ are likely to be related to the thermocline variability (Qu et al., 2004). The most notable cold and warm anomalies occurred in 1964 and 2000, respectively. In addition, the temperature appears to have risen in the recent decades.

For the comparison of XBT data and the SODA product, nine boxes are chosen where the XBT data are abundant. The results show that the two data sets are comparable in terms of heat content (not shown here), and an example (the entire SCS) is given in Fig. 2. The XBT data and the SODA product have similar variability, especially in terms of OHC time series (Fig. 2, bottom). So, only the SODA product will be used next for heat budget calculation. 


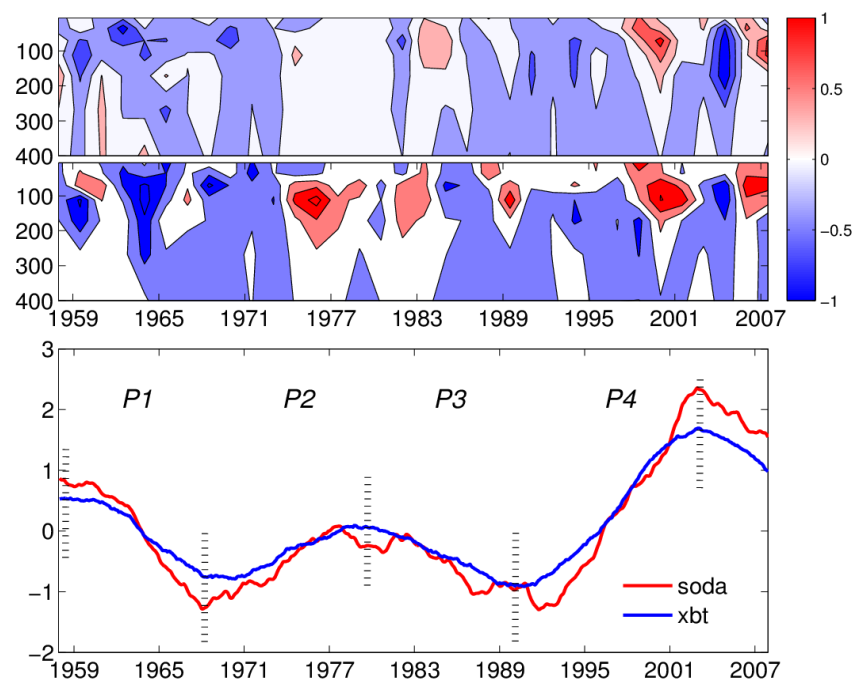

Fig. 2. Temperature anomalies of the whole South China Sea (contour interval: 0.2 , units: $\mathrm{K}$; seasonal cycle removed) of the XBT (top) and SODA (middle), and the heat-content time series of XBT and SODA (bottom), units: $10^{23} \mathrm{~J}$. Also indicated are P1: 19581968; P2: 1969-1981; P3: 1982-1992; and P4: 1993-2003.

Table 1. The terms of heat budget for the climatological mean and in the four periods shown in Fig. 2. HCC denotes heat-content change in the upper $400 \mathrm{~m}$. QNET (positive into the SCS) denotes the net surface heat flux. ADV (positive into the SCS) is the ocean heat advection, and $R$ is the residual heat flux (vertical advection, diffusion, etc.). Units: $\mathrm{TW}$, where $1 \mathrm{TW}=10^{12} \mathrm{~W}$.

\begin{tabular}{lrrrr}
\hline & HCC & QNET & ADV & $R$ \\
\hline Clim & 3.38 & 67.69 & -51.10 & -13.28 \\
P1 & -18.72 & 2.53 & -14.92 & -6.33 \\
P2 & 14.36 & -1.77 & 13.23 & 2.90 \\
P3 & -15.53 & -7.24 & -4.87 & -3.42 \\
P4 & 24.31 & 16.69 & 3.45 & 4.17 \\
\hline
\end{tabular}

\subsection{Heat balance}

According to the decadal variability of OHC in the SCS (Fig. 2, bottom), four periods are chosen for studying the heat budget, which are 1958-1968, 1969-1981, 1982-1992, and 1993-2003 (Table 1). All terms in the heat equation except the diffusion are calculated using the SODA product as in $\mathrm{Na}$ et al. (2012). The advection term is the summation of fluxes through the four channels (Luzon Strait: $120.25^{\circ} \mathrm{E}, 18.25-$ $22.25^{\circ} \mathrm{N}$; Taiwan Strait: $117.25-120.25^{\circ} \mathrm{E}, 20.25^{\circ} \mathrm{N}$; Sunda Shelf: $104.25-111.25^{\circ} \mathrm{E}, 1.75^{\circ} \mathrm{N}$; Mindoro Strait: $117.25-$ $\left.120.25^{\circ} \mathrm{E}, 6.75-14.75^{\circ} \mathrm{N}\right)$. The Luzon Strait fluxes are positive every period and the other three fluxes are all negative every period, but between the different periods the value of each strait's flux varies; the contribution of ADV (four straits' summation) to HCC is different. The climatological heat budget is consistent with a previous study based on the

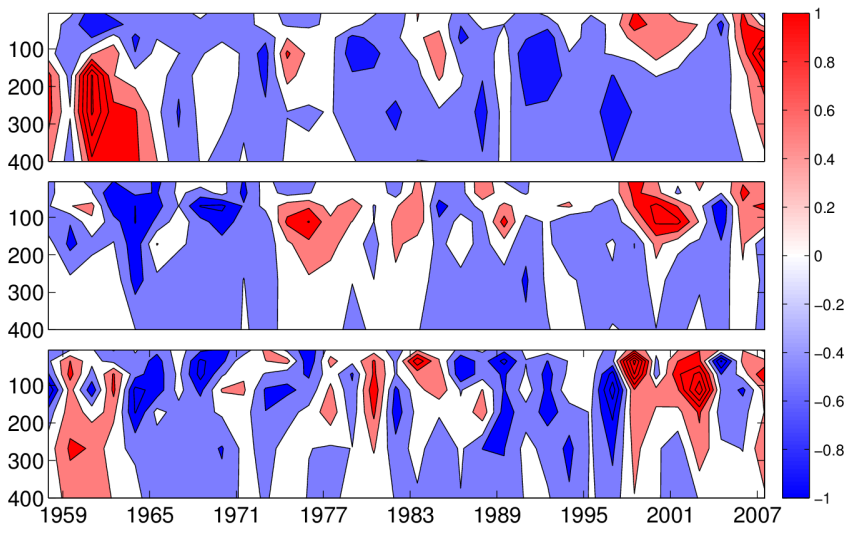

Fig. 3. Temperature anomalies (contour interval: 0.2, units: K; seasonal cycle removed) of Box 1 (top), Box 2 (middle), and Box 3 (bottom).

results from an ocean general circulation model $(\mathrm{Qu}$ et al., 2004); climatological HCC, $Q$ and ADV in Table 1 are each within $93 \%$ of the model values.

Inferred from the terms in Table 1, the significant factors controlling the heat content change (HCC) in the SCS differ for the four chosen periods. During 1958-1968 (period $\mathrm{P} 1)$, the OHC in the SCS decreased rate was $-18.72 \mathrm{TW}$, and cannot be explained by the net surface heat flux, which was $2.53 \mathrm{TW}$ into the ocean. So the advective cooling was the major contributor to the HCC in this period. Advection can also explain the increase in OHC during 1969-1981 (period P2). Advection was the major factor causing the heat content variation before the climate shift in 1976, explaining up to $78 \%$ and $93 \%$ of the change in periods $\mathrm{P} 1$ and $\mathrm{P} 2$, respectively. The situations are different after the climate shift during periods $\mathrm{P} 3$ and $\mathrm{P} 4$, when the net surface heat flux played an important role in regulating the decadal variability during 1982-1992 and 1993-2003, although the contribution of advection cannot be ignored, with $31 \%$ and $14 \%$, respectively, for these periods. After the climate shift, the net heat flux and ocean heat advection can explain about $78 \%$ and $83 \%$ of the HCC during 1982-1992 and 1993-2003, respectively, and the rest of HCC may be caused by vertical flux and diffusion. There was an evident positive trend in $\mathrm{OHC}$ from 1992 to 2003, which was stronger than the HCC in the years from 1982 to 1992 and was mainly caused by the strong cold anomaly in 1992 and warm anomaly in 2003 (Fig. 2, bottom panel).

\subsection{Spatial differences}

When comparing XBT data and the SODA product, we found that the HCCs in different areas have a general resemblance (Figs. 3 and 4). Three key boxes (shown in Fig. 1) are chosen to study the spatial characteristics of $\mathrm{OHC}$ and its budget due to HCC, net heat flux and advection. The boxes are for the Luzon strait, west of Luzon Island, and 


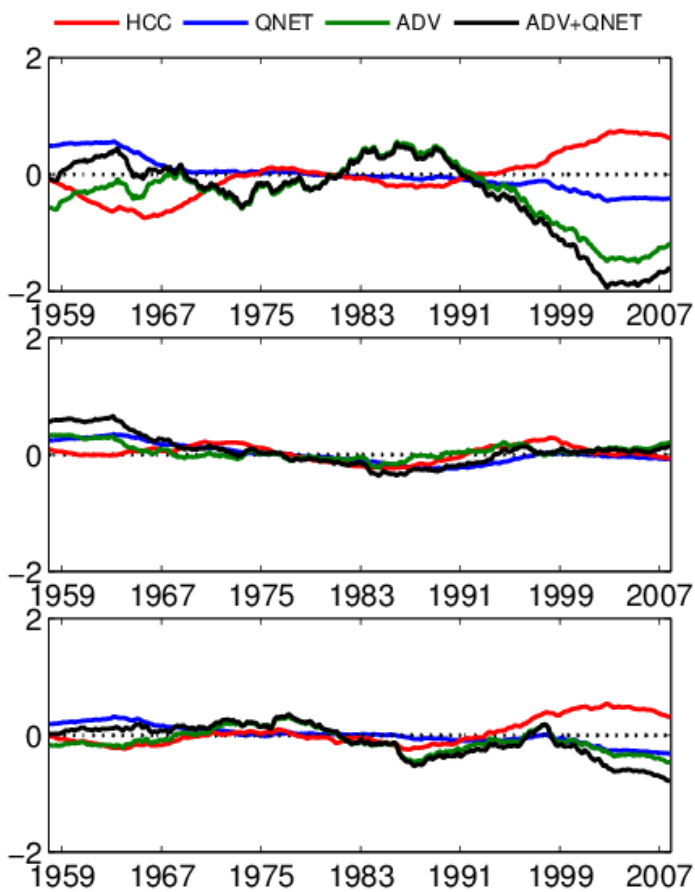

Fig. 4. Time series of $10 \mathrm{yr}$ running mean $\mathrm{HCC}$ (red), QNET (blue) and ADV (green) in Box 1 (top), Box 2 (middle) and Box 3 (bottom); units: $\mathrm{TW}$, where $1 \mathrm{TW}=10^{12} \mathrm{~W}$.

the Xisha warm eddy region. It seems that the warming happened both in the subsurface and the surface near the Luzon Strait (Fig. 3, upper panel), but the data before the 1970s should be used carefully, so the detailed characteristics should be investigated further. The net heat flux and advection cannot explain the variability of $\mathrm{OHC}$ in the $\mathrm{Lu}-$ zon Strait, which is mainly affected by the Kuroshio Current; the dynamical processes here are complicated (such as a strong Kuroshio associated with meso-scale eddy and diffusion, etc.). Both boxes 2 and 3 are located in the interior SCS and influenced by the Pacific Ocean, but each has its own characteristics. The box we choose in the Xisha warm eddy is the pathway of the western boundary current of the South China Sea (SCS) and the SCS warm current; the heat content change here is mainly caused by the advection flux. The box we choose to the west of Luzon Island is connected to the Pacific Ocean through the Mindoro Strait and other marginal seas. Some research shows that the Pacific water and signal can get into the SCS through the Mindoro Strait (Zhuang et al., 2013). The temperature profile in Box 3 (Xisha warm eddy) has some similarity with that in Box 2 (west of Luzon Island), but the oscillation of temperature in Box 3 is more vigorous than that in Box 2 (Fig. 3, bottom and middle panels). The results of the heat budget show that advection is the major contributor to the HCC in boxes 2 and 3, with similar trends especially from the 1970s to 1990s (Fig. 4, middle and bottom panels). The net surface heat flux decreased during the study period, and advection seems to dominate the HCC in the SCS (Qiu and Chen, 2012).

\section{Summary and discussion}

Using the SODA, XBT, and NCEP/NCAR flux data sets, the decadal variability of OHC in the SCS was discussed. The results show that the decadal variability of $\mathrm{OHC}$ is evident, with two peaks and troughs during the study period. The OHC in the whole SCS decreased in 1958-1968 and 19821992, and increased in 1968-1981 and 1993-2003. Before the climate shift in 1976, the advection was the major factor in the heat content variation, with $78 \%$ and $93 \%$ contributions in periods $\mathrm{P} 1$ and $\mathrm{P} 2$, respectively. The situations were different after the climate shift, and the net surface heat flux played an important role in regulating the decadal variability during 1982-1992 and 1993-2003, although the contributions of advection cannot be ignored, at $31 \%$ and $14 \%$, respectively.

In this paper, the spatial characteristics of the $\mathrm{OHC}$ in the SCS were also discussed. In the Luzon Strait, the net heat flux and advection could not account for the variability of OHC there, perhaps due to the complicated ocean dynamic processes, such as strong Kuroshio and associated mesoscale eddies and diffusion. The trends of HCC and net heat flux in the study period were negative, and it is difficult to explain the HCC with the net heat flux alone. In fact, the advection was the main factor to control the decadal variability of the OHC in the interior SCS, especially during the 1970s to 1990 s.

The OHC time series actually indicates that the timing of the OHC minimum matched a volcanic eruption. Church et al. (2005) noted that after a volcanic eruption, the volcanic ash can be sent into the stratosphere and remain stable; thus, the solar radiation can be reduced, leading to decreased heat content in the ocean. For either the whole SCS or the boxes chosen, however, the local solar radiation does not match the OHC variability. Each volcanic eruption affects the global solar radiation, and then the global OHC; the effect on the SCS is in another form (i.e., advection dominated by atmospheric circulation) (Tozuka et al., 2009). The Mt. Pinatubo eruption that occurred near the SCS in 1992 may be partly responsible for the greatest cold anomaly in the $\mathrm{OHC}$ seen in Fig. 2 (bottom).

Acknowledgements. This research was supported by the National Basic Research Program of China (2011CB403502), by the National Nature Science Foundation of China under grants 41306014, 41206011, and 41221063, and by the Guangzhou Municipal Science and Technology Project under grant 12F084060027. Qinyan Liu is supported by the open program of The First Institute of Oceanography, SOA (grant: LDAA-2012-03). The authors wish to thank the reviewers and editors for their valuable constructive comments.

Edited by: J. M. Huthnance 


\section{References}

Carton, J. A. and Giese B. S.: A Reanalysis of Ocean Climate Using Simple Ocean Data Assimilation (SODA), Mon. Weather Rev., 136, 2999-3017, 2008.

Carton, J. A., Chepurin, G., Cao, X., and Giese, B.: A simple ocean data assimilation analysis of the global upper ocean 1950-95, Part I: Methodology, J. Phys. Oceanogr., 30, 294-309, 2000a.

Carton, J. A., Chepurin, G., Cao, X., and Giese, B.: A simple ocean data assimilation analysis of the global upper ocean 1950-95. Part II: Results, J. Phys. Oceanogr., 30, 311-329, 2000 b.

Church, J. A., White, N. J., and Arblaster, J. M.: Significant decadalscale impact of volcanic eruptions on sea level and ocean heat content, Nature, 438, 74-77, doi:10.1038/nature04237, 2005.

Domingues, C. M., Church, J. A., White, N. J., Gleckler, P. J., Wijffels, S. E., Barker, P. M., and Dunn, J. R.: Improved estimates of upper-ocean warming and multi-decadal sea-level rise, Nature, 453, 1090-1093, doi:10.1038/nature07080, 2008.

Fang, G. H., Wei, Z. X., Choi, B. H., Wang, K., Fang, Y., and Li, W.: Inter-basin freshwater, heat and salt transport through the boundaries of the East and South China seas from a variable-grid global ocean circulation model, Sci. China, Ser. D, 46, 149- 161, 2003.

Gouretski, V. and Koltermann K. P.: How much is the ocean really warming?, Geophys. Res. Lett., 34, L01610, doi:10.1029/2006GL027834, 2007.

He, Y. and Guan, C.: Interannual and interdecadal variability in heat content of the upper ocean of South China Sea, Trop. Oceanol. 16, 23-29, 1997.

Levitus, S., Antonov, J., Boyer, T., and Stephens, C.: Warming of theworld ocean, Science, 287, 2225-2229, doi:10.1126/science.287.5461.2225, 2000.

Levitus, S., Antonov, J., and Boyer, T.: Warming of the world ocean, 1955-2003, Geophys. Res. Lett., 32, L02604, doi:10.1029/2004GL021592, 2005.

Levitus, S., Antonov, J. I., Boyer, T. P., Locarnini, R. A., Garcia, H. E., and Mishonov, A. V.: Global ocean heat content 1955-2008 in light of recently revealed instrumentation problems, Geophys. Res. Lett., 36, L07608, doi:10.1029/2008GL037155, 2009.

Liu, Q., Huang, R., and Wang, D.: Implication of the South China Sea throughflow for the interannual variability of the regional upper-ocean heat content, Adv. Atmos. Sci., 29, 54-63, 2012.

Locarnini, R. A., Mishonov, A. V., Antonov, J. I., Boyer, T. P., and Garcia, H. E.: World Ocean Atlas 2005, 3-6, in: NOAA Atlas NESDIS 61, Vol. 1, edited by: Levitus, S., Government Printing Office, Washington, DC, 2006.
Na, H., Kim, K.-Y., Chang, K.-I., Park, J. J., Kim, K., and Minobe, S.: Decadal variability of the upper ocean heat content in the East/Japan Sea and its possible relationship to northwestern Pacific variability, J. Geophys. Res., 117, C02017, doi:10.1029/2011JC007369, 2012.

Qiu, B. and Chen, S.: Multidecadal sea level and gyre circulation variability in the northwestern tropical Pacific Ocean., J. Phys. Oceanogr., 42, 193-206, 2012.

Qu, T., Kim, Y. Y., Yaremchuk, M., Tozuka, T., Ishida, A., and Yamagata, T.: Can Luzon Strait transport play a role in conveying the impact of ENSO to the South China Sea?, J. Climate, 17, 3644-3657, 2004.

Smith, R. D., Dukowicz, J. K., and Malone, R. C.: Parallel ocean general circulation modeling, Phys. D: Nonlinear Phenomena, 60, 38-61, 1992.

Tozuka, T., Qu, T., Masumoto, Y., and Yamagata, T.: Impacts of the South China Sea Throughflow on seasonal and interannual variations of the Indonesian Throughflow, Dyn. Atmos. Oceans, 47, 73-85, 2009.

Wang, D., Liu, Q., Huang, R., Du, Y., and Qu, T.: Interannual variability of the South China Sea throughflow inferred from wind data and an ocean data assimilation product, Geophys. Res. Lett., 33, L14605, doi:10.1029/2006GL026316, 2006a.

Wang, Y., Fang, G., Wei, Z., Qiao, F., and Chen, H.: Interannual variation of the South China Sea circulation and its relation to El Niño, as seen from a variable grid global ocean model, J. Geophys. Res., 111, C11S14, doi:10.1029/2005JC003269, 2006 b.

Willis, J. K., Roemmich, D., and Cornuelle, B.: Interannual variability in upper ocean heat content, temperature, and thermosteric expansion on global scales, J. Geophys. Res., 109, C12036, doi:10.1029/2003JC002260, 2004.

Yan, Y., Qi, Y., and Zhou, W.: Interannual heat content variability in the South China Sea and its response to ENSO, Dynam. Atmos. Oceans, 50, 400-414, 2010.

Zhuang, W., Qiu, B., and Du, Y.: Lowfrequency western Pacific Ocean sea level and circulation changes due to the connectivity of the Philippine Archipelago, J. Geophys. Res. Oceans, 118, 6759-6773, doi:10.1002/2013JC009376, 2013.

Zong, H., Liu, Y., Xiu, P., Xu, Q., and Rong, Z.: Interannual variability of latent and sensible heat fluxes in the South China Sea, Chinese J. Ocean. Limnol., 28, 153-159, doi:10.1007/s00343010-9241-9, 2010. 